\title{
La primera vez que, en abril de 1973, Jorge Luis Borges visitó la sede de la Real Academia Española y "compartió" con los académicos españoles, según AZV, Secretario Perpetuo de la Institución
}

Juan Manuel González Martel ${ }^{1}$

Recibido: 8 de febrero de 2017 / Aceptado: 4 de octubre de 2017

Resumen. El autor da cuenta de la visita de Jorge Luis Borges a la Real Academia Española, en 1973, y de la escasa presencia de los académicos ante la llegada de tan ilustre creador argentino.

Palabras clave: Alonso Zamora Vicente; Jorge Luis Borges; Real Academia Española.

[en] Jorge Luis Borges's first time visit to the Real Academia Española, in April, 1973

Abstract. The author describes Jorge Luis Borges's first time visit to the Real Academia Española, while Alonso Zamora Vicente was there as Secretario Perpetuo. It was a very remarkable date because no one was expecting him.

Keywords: Alonso Zamora Vicente; Jorge Luis Borges; Real Academia Española.

Sumario: 1. Introducción; 2. Zamora Vicente y las literaturas iberoamericanas; 3 La inesperada visita de Jorge Luis Borges a la RAE; 4. ¿Primera visita y última de Jorge Luis Borges?; 5. Del brazo del Secretario Perpetuo; 6. "Cuando resuena el tango...”; 7. "Como aprendí en aquel poema de Borges"; 8. Fuera de itinerario, dos citas para una contestación, cuarenta y tres años después y en el mismo lugar; 9. Referencias bibliográficas.

Cómo citar: González Martel, J. M. (2017). La primera vez que, en abril de 1973, Jorge Luis Borges visitó la sede de la Real Academia Española y "compartió" con los académicos españoles, según AZV, Secretario perpetuo de la Institución, en Revista de Filología Románica 34. Núm. especial, 163-170.

\section{Introducción}

En la biografía del escritor y filólogo romanista Alonso Zamora Vicente (19162006), uno de los apartados menos conocidos es el concerniente al cargo de Secretario Perpetuo de la Real Academia Española, en una etapa de gestión inmediata-

1 Profesor jubilado de la Universidad Complutense de Madrid y exdirector conservador de la Casa-Museo de Lope de Vega

Email: jmgmartel@hotmail.com 
mente anterior a la reforma de 1993 del Estatuto académico. Cuando se estudie la actividad desarrollada por Zamora Vicente desde este puesto directivo quedará mejor definida su influencia en la Corporación y, en razón de la importancia internacional de nuestro idioma y del prestigio de la histórica Institución, se destacará la repercusión que algunas de sus acciones como Secretario de la Real Academia alcanzaron no sólo en la transformación de la Corporación sino también, con sus gestiones personales o en el control de la Asociación de las Academias y sus Congresos, en el ámbito hispano.

Igualmente, en ese marco de acciones en favor de la lengua española, se subrayarán muchas noticias académicas relativas al trabajo cultural, un contexto en el cual también cobrará entidad el anecdotario que, en ocasiones, lo ilustra. Un sugestivo noticiero, en fin, que perfilarán asimismo su personalidad académica y completará la nómina de gente que trató. Y de esa variopinta de información, elijo para este I Itinerario Artístico y Literario de Alonso Zamora Vicente en Cáceres, Malpartida de Cáceres y Madrid $^{2}$, un breve episodio que, a pesar de la ficción que parece envolverlo, se ajusta a una situación real y, concretamente, se inscribe en la admiración de Zamora Vicente, por las literaturas hispanoamericanas.

\section{Zamora Vicente y las literaturas iberoamericanas}

Alonso Zamora Vicente - como nuevamente habían comprobado sus estudiantes de Doctorado del curso de 1970-1971, en la Facultad de Filosofía y Letras de la Universidad Complutense-, continuaba, como historiador de las literaturas hispánicas, con el estudio del alcance del Modernismo, y, en esos capítulos de sus amplios intereses lingüísticos y literarios, interpreté la aceptación de la investigación que, como asunto de mi tesis, le había propuesto sobre el cronista guatemalteco Enrique Gómez Carrillo (1873-1927). Como el estudio que proponía ya había sido rechazado, siempre con buenas palabras, por otros profesores, además de la deferencia universitaria de Zamora Vicente para quien no había sido alumno suyo en la licenciatura, su aprobación me la expliqué, asimismo, como una muestra de la apertura intelectual de quien valoraba las letras de los países americanos.

\section{La inesperada visita de Jorge Luis Borges a la RAE}

Tal opinión sobre el magisterio del filólogo madrileño quedó reforzada pocos meses después con el ejemplo que, como anécdota transformada en lección magistral, supuso una situación ocurrida en la sede de la Real Academia Española, en el reencuentro, en 1973, de Borges con Zamora Vicente. Se habían conocido en Buenos Aires, durante la estancia del filólogo español entre 1949 y 1952 . Una voluntaria baja habida a lo largo de 1972 en el pequeño grupo de lexicógrafos de la Corporación dejó vacantes unas cuantas plazas de colaboradores que convenía cubrir lo antes posible, puesto que ya era escaso el número de empleados para las labores de 
los Diccionarios. Y como entre los cambios de cargos académicos, el más destacado había sido la renuncia de Rafael Lapesa a la Secretaría y el nombramiento en ese 1971 del académico Alonso Zamora Vicente para el puesto, la urgencia llevó a los miembros de la Junta de Gobierno a encargar a ambos profesores, catedráticos en activo por entonces, a seleccionar a algunos de sus estudiantes de la Universidad Complutense. Y así, en 1972, a lo largo de unos meses a unos cuantos licenciados en Filología Románica y en Hispánicas, que habían finalizado los cursos de Doctorado, se les propuso aprender de manera más sistemática las labores lexicográficas que se aplicaban a los Diccionarios académicos. Así empezamos algunos a trabajar en la RAE.

Llevábamos en las labores lexicográficas unos ocho meses, cuando, a finales de abril de 1973, Zamora Vicente, en una de aquellas tardes, se dirigió a los tres colaboradores con los que había coincidido en el vestíbulo de la biblioteca académica. Nos dijo que esperaba una visita; que probablemente pidiese algún libro o algunas papeletas de palabras en preparación; que estaría en el despacho del Director; y que, con el visitante y algunos académicos, pasaría por los lugares de trabajo. En esos años, repartidos por algunas salas del caserón académico, trabajaban los colaboradores de la revisión de las ediciones en marcha de los diccionarios "oficiales". Los experimentados, para el Histórico, y los de incorporación más reciente, en la edición del diccionario Usual. Licenciados o doctores, la mayoría eran profesores de enseñanza secundaria, con horarios de mañana. Avanzada la tarde, tal como era por entonces una de mis obligaciones, entregaba los borradores de consultas gramaticales y léxicas en la oficina del Oficial Mayor. Zamora Vicente estaba allí, hablando por teléfono. Y cuando colgó me comentó que la visita esperada había sido aplazada. La conversación terminaba así:

Si usted quiere, iré a buscarle al hotel [Ritz]. Estamos al lado. La entrada a la Casa es por Felipe IV, esta calle que sube, de la fuente de Neptuno al Retiro, entre el edificio de su hotel y el de la Academia.

Apenas había colgado el teléfono, me pidió que dejase las contestaciones a las consultas lingüísticas para más tarde, y que fuese, como él tenía que continuar con las llamadas, a la biblioteca:

- Compruebe qué hay de sus libros, y las fechas de las ediciones, dijo.

- Obras..., de quién, pregunté.

- ¡Ah, perdone! Pensaba que se lo había dicho, respondió. Es Borges, Jorge Luis Borges. ;Anote todo lo fichado a su nombre, libro o revista! No creo que haya mucho... Ya usted sabe de las sorpresas de nuestro acervo. Tenemos ediciones que pocas bibliotecas poseen y, sin embargo, carecemos aún de la obra completa de algunos de nuestros literatos fundamentales.

Escuchado el nombre, nunca había subido tan velozmente la escalinata principal, ni pasado tan despistado por delante del Quevedo, con gafas, de Querol ${ }^{3}$ que la adorna.

3 Agustín Querol y Subirats (1860-1909) es el autor de la escultura de Francisco de Quevedo de 1902 instalada en la glorieta madrileña del mismo nombre, cuya réplica se encuentra en la Real Academia Española. 
- Confirmeme lo que hay en la biblioteca. ¡No vaya a tener que traerme alguna edición de casa!, añadió.

Consultado el fichero, volví, con un decepcionante resultado anotado. Y me vino a la mente la completa bibliografía que había visto manejar a un joven poeta colombiano, condiscípulo de Doctorado, que había preparado, matriculado en la Universidad Complutense, una tesis ${ }^{4}$ sobre Jorge Luis Borges.

Hace unas semanas se difundieron unas justas opiniones de Vargas Llosa sobre Borges. Los titulares sobre lo dicho por el escritor peruano reproducían rotundas frases sobre la importancia del escritor. Eran apreciaciones que escuché con satisfacción pero que, al minuto, me hicieron sonreír. Al entusiasta Vargas Llosa, que se doctoró en la Universidad Complutense dirigido por Zamora Vicente, lo imaginé repasando, y seguro que más sorprendido que yo por haberlo conocido de mucho antes, los autores del viejo fichero académico. Don Alonso, más que atender a los progresos de su Flaubert o Emma Bovary, no hubiese tenido que convencerle para que aquel día esperase un ratillo para saludar al académico argentino.

\section{4. ¿Primera visita y última de Jorge Luis Borges?}

Un ejercicio de ficción literaria parecería si el Secretario no se hubiese animado a notificarlo con tres líneas en el Boletín de la Real Academia Española. Como no consta en la correspondiente Acta oficial, es una circunstancia biográfica poco divulgada. Se notifica un hecho que por su descontextualización parece ser información sólo de consumo académico interno, y, aun así, como noticia resulta muy escueta. La noticia, a cuatrimestre cumplido, apareció en el apartado de la "Memoria académica" de dicho Boletín. ¿Unas fáciles líneas de simple cliché de redacción periodística, pero con un dato principal cambiado: supuesta presencia de otros académicos durante la visita; un párrafo con "bicho dentro" - como advierte el título de uno de sus libros- o una señal de que la presencia de Borges en la Real Academia Española suponía una anomalía para alguien de una sensibilidad política o personal extremas?

\section{Del brazo del Secretario Perpetuo}

En la retina, la seguridad al caminar de Borges del brazo de Zamora Vicente, atento a todo aquello que le era contado, como si hubiese sido elaborado expresamente como una guía de la Real Academia para que el creativo literato la "imaginase" en sus pormenores.

Como la visita había sido pospuesta, Zamora Vicente tuvo tiempo aquella tarde de hacer nuevas llamadas a algunos de esos miembros de la Academia menos "literarios", los "técnicos". Hacia las once de la mañana se confirmó que el Director, cuyo mal no había remitido, continuaba a resguardo. Y en ese reposo, tal vez Dámaso Alonso recordaría sus disensiones sobre nuestros barrocos con el escritor argentino. Lejano todavía 1979, cuando la propuesta española para el Premio Cervantes tendría que competir

4 Harold Alvarado Tenorio, Doctor de Filología Románica por la Universidad Complutense. Esta tesis, dirigida por Zamora Vicente, fue una de las primeras sobre Borges presentadas en la Facultad madrileña. 
con la sorpresa de la decidida presentación de la candidatura de Borges por la Academia Argentina de Letras. ¿Gerardo Diego o Jorge Luis Borges? La solución del jurado: un premio compartido por primera vez. Y la prensa, un pelín despistada en las comparaciones y reparto de elogios de un Cervantes dividido.

$\mathrm{Y}$ en el amplio frente, de los miembros de número... Si bien no era obligatorio según las bases... haber leído a Borges, el Secretario no había conseguido ningún "académico" que lo acompañase... Qué hacer. Pues lo propio, lo reglamentario. Si no hay Director, siempre habrá Perpetuo... Y, como compensación, Zamora solía declarar, cuando se hablaba del mucho trabajo del Secretario - prácticamente tenía que asistir a todas las juntas y comisiones- que el cargo tenía también muchas satisfacciones. Y el rencuentro con Borges podía tenerse como una de las gratificantes. Finalmente, la ausencia académica llevaba las de ganar para convertir la visita en una corriente anécdota más de la cultural oficial... Pero lo que nos tenía expectantes era qué haría Zamora Vicente.

\section{6. "Cuando resuena el tango..."}

Unos minutos para la hora acordada. Y Zamora se dispuso a la espera del viejo conocido. ¡No me hubiese extrañado que en esos momentos intentase recordar algún detalle de "Cuando resuena el tango (carta a un amigo argentino)", artículo para La Nación, o que ¡canturrease alguna desgarrada letra porteña! Hasta el último momento esperó a Dámaso Alonso, y hasta el último vistazo hacia la puerta tuvo esperanza de que apareciera alguno de los colegas.

Borges fue puntual. Efusivo su saludo. Y Zamora Vicente, tomándolo del brazo, se dirigió al despacho del Director. En pleno vestíbulo, ese espacio central del edificio, aún sin mullida gruesa alfombra ni la cubierta de coloridos vidrios, el Secretario transmitía el lamento de Dámaso. "Un enfriamiento. Le envía sus saludos y le desea una buena estancia madrileña". Después de unos tres cuartos de hora, nos avisaron para que fuésemos al despacho.

- Estos colaboradores del Diccionario nos acompañarán, por si usted me hace alguna pregunta dificil sobre cómo son los trabajos previos de ir organizando las definiciones o el orden de las acepciones. ;Ya usted sabe! Lo más pesado, o sobre la Casa y sus miembros... Estos jóvenes profesores universitarios saben más que los académicos..., informó.

Y después de pronunciar nuestros nombres, Zamora, como si de colegas suyos en la Corporación se tratase, fue atribuyéndonos imaginarios cargos, relacionados con las tareas lexicográficas, que no se correspondían con ningún escalafón, méritos o nómina... Zamora Vicente ya había empezado a contarle algunas particularidades de la Academia. De aquel despacho siempre destacaba el magnífico Conde de Cheste $^{5}$, del pintor Vicente López, que adorna el despacho. Y sobre la mesa, bien aislado, sobresalía el retrato de Santa Teresa ${ }^{6}$, que había traído de la habitación con-

Juan de la Pezuela y Ceballos (1809-1906), marqués de la Pezuela y Conde de Cheste, retratado por Vicente López (1772-1850) hacia 1849, fue nombrado director de la institución en 1875.

6 Es retrato de autor anónimo, contemporáneo de la santa (1515-1582), semejante a otro de Fray Juan de la Miseria que se encuentra en el convento de las Carmelitas Descalzas de Valladolid encargado en 1582. 
tigua, como si hubiese querido que Borges lo tuviese en sus manos, y quizás para describirle la austeridad de los rasgos de la cara de la santa: "Ambos retratos, tan distintos, son lo mejor de nuestro patrimonio", añadió.

Y empezó el paseo por las dependencias, describiéndole el edificio, adornando su explicación con irónicos comentarios de buen historiador. Enumeró el contenido de los dos expositores centrales, con detalles sobre los objetos usados en la inauguración de $1894^{7}$ y la chatarra de la coronación de Zorrilla ${ }^{8}$, como poeta nacional, la colección de la Ortografía, la edición de Ibarra del Quijote ${ }^{9}$, junto a las terracotas de bustos de los personajes de la novela, las obras de Lope de Vega, el Diccionario de Autoridades; el salón de plenos, con la mesa ovalada de Hartzenbusch, y el salón de espera o de estar, "el de pastas", el de los refrigerios de los jueves, donde los académicos departen entre sesiones, en cuyas paredes continuaban los cuadros de la galería de retratos de los directores. Y la escalinata, con el Quevedo. El salón de actos, el discutido retrato de Cervantes, la decoración pompeyana y las vidrieras. Y por todas partes, los cajetines del gran fichero... En la planta principal, en la sala de trabajo del Histórico, Zamora saludó a otros colaboradores, a quienes preguntó cómo iban esos "controles" o apuntaba al mucho "histórico" que quedaba por publicar...

En la charla fue surgiendo la inevitable comparación con lo vivido en Buenos Aires. Referencias porteñas, minuciosas, cuando se pregunta por el destino de las personalidades de aquel prestigioso Instituto -donde están ahora, qué hacen...-, o por los cambios de los barrios frecuentados. Zamora le hablaba de Sol o Los Jerónimos y Borges recuperaba Palermo o Recoletas. Y la calle de Rivadavia, siempre Rivadavia, la dirección de don Alonso. Escuchábamos. Y de lo dicho nos sorprendió que Zamora dijese que como escritor se había iniciado en la capital bonaerense, en La Nación. Y aunque sabíamos que su principal aval era la fundación de la revista Filología del Instituto de Filología de la Faculta de Filosofía y Letras de Buenos Aires, continuación de la Revista de Filología Hispánica (1938-1946), él, a modo de valiente juicio, dio una valoración de la revista, de la calidad alcanzada por un centro de investigación lingüística y literaria americano como había sido el Instituto de Filología de la Universidad de Buenos Aires, "centro del hispanismo continental", y que el mérito era atribuible exclusivamente al pulso de los estudiosos argentinos. El recorrido, pausado, un sinnúmero de detalles académicos comentados con sus tonos de voz, el contraste de sus entonaciones, los siempre presentes pronombres de cortesía, e incluso, por tres ocasiones, canturreo de letrillas tradicionales.... Realmente, Zamora Vicente logró que la Academia de aquella mañana fuese, sin otro recurso que el de su palabra, con su manera de presentar la historia de la Casa, uno de los lugares ideales de la cultura de la lengua española.

\section{7. "Como aprendí en aquel poema de Borges"}

La noticia se publicó semanas después, en el cuaderno del Boletín de la Real Academia Española, en la "Información académica". Después de notificar de otra visita, escribe:

La inauguración de la sede de la RAE, que tuvo lugar el 1 de abril de 1894, estuvo presidida por la reina regente María Cristina y Alfonso XIII.

8 La coronación de José Zorrilla se celebró el 16 de junio de 1889 en el Palacio de Carlos V de Granada.

9 La RAE decidió en 1773 publicar la edición definitiva del Quijote, factoría impresa por Ibarra. 
También el día 27 de abril, la Real Academia Española recibió la visita del ilustre escritor argentino Jorge Luis Borges, miembro de número de la Academia Argentina de Letras. El Sr. Borges recorrió las dependencias de la Casa y compartió con los académicos españoles.

Así pues, una escueta noticia "aumentada": un ilustre escritor, correspondiente argentino, había sido recibido "por la Real Academia Española”, recorrió la Casa y la "compartió" con los académicos. Zamora Vicente finalizó con la sonriente broma, que ya le habíamos escuchado en alguna ocasión. Un comentario de orgullo cultural de su ciudad, de su país, y que esta vez le fue contestado:

- Poca cosa más que contarle. Habrá nueva ocasión de reanudar nuestra conversación, estimado amigo. Saludos para todos los compañeros de la independiente y laboriosa Academia Argentina de Letras. Tal vez nuestra única ventaja sea la cercanía del Prado, con vecinos como Velázquez y Goya... Y de momento de libre entrada...

A lo que Borges, con afable palabra, y eficaz ironía porteña, como remate, de quien había comprendido perfectamente, desde el principio, la situación, habría de contestar:

- Ha sido buena idea haber venido a verle. Muchas gracias, de nuevo.

Y verdaderamente es una maravilla tener tan a mano El Prado, a esos geniales pintores. Para conocerlos mejor; para poder preguntarles aún por tantos secretos.

¿Y vos sabés, muy apreciado Zamora Vicente, si son muchos sus colegas que aprovechan esta vecindad del Museo para saludar a nuestros prodigiosos artistas?

Una sonrisa cómplice y un discreto abrazo los unió en la puerta de Felipe IV, como eco de aquel desdoblamiento del personaje del cuento "Apiguaytay" (1955), de Smith y Ramirez, S. A. (1957).

Si en abril de 1973 fue una satisfacción para Zamora Vicente la visita del escritor argentino y para Borges el estar en la Real Academia Española guiado por un amigo, para nosotros fue un veloz rato únicamente pendiente de aquellos vos y usted del recorrido de Borges por la Real Academia del brazo de Zamora Vicente. Convertidos así en ideales paseantes tuvimos la suerte de repetirnos silenciosamente el diálogo entre la voz y la visión de Alonso Zamora Vicente y de Jorge Luis Borges. Finalmente, no hizo falta más coro.

\section{Fuera de itinerario, dos citas para una contestación, cuarenta y tres años después y en el mismo lugar}

El pasado 29 de enero, sorpresa, y complacencia, al escuchar tanto a M. ${ }^{\text {a Paz Batta- }}$ ner Arias, en la lectura de su discurso de recepción en la RAE, Algunos pocos sin fondo de los diccionarios, como en la contestación de Ignacio Bosque, sendas citas de Jorge Luis Borges. Y al nombrar a Borges, esos académicos - Battaner, una sobresaliente filóloga romanista, que tuvo a Zamora Vicente entre sus maestros, y, Bosque, un innovador gramático, a quien su entrega a la investigación no le impide volcarse cada día más en la escritura de creación, y que trató al viejo profesor madrileño- representaban, en esa tarde de dicho acto académico, a los nuevos que, con 
renovada lectura, frecuentaban a los grandes creadores americanos del idioma de todos.

\section{Referencias bibliográficas}

Battaner Arias, Ma Paz (2017): Algunos pozos sin fondo en los diccionarios. Discurso leído el día 29 de enero de 2017 en su recepción pública por [...] y contestación del Excmo. Sr. Ignacio Bosque. Madrid: RAE, disponible en http://www.rae.es/sites/default/files/Discurso_ingreso_Paz_Battaner.pdf [consulta 15/10/2017].

Real Academia Española (1973): “Memoria académica". Boletín de la Real Academia Española. Madrid: RAE.

Zamora Vicente, Alonso (1956): "Cuando resuena el tango (carta a un amigo argentino)". La Nación (15/04/1956). Buenos Aires.

Zamora Vicente, Alonso (1957): “Apiguaytay”, in Smith y Ramírez, S. A. Valencia: Castalia. 